\title{
The role of workflow and marketing resource management technologies in supporting marketing - The last bastion for technology in marketing
}

Received: 14th July, 2003

\section{Shaun Doyle}

is CEO of Cognitive Box, a marketing technology solution provider. He was formerly VP Intelligent Marketing Solutions at SAS. In this role he worked with various parts of the SAS organisations to develop business-oriented solutions for marketing, in particular the SAS Marketing Automation (MA) Solution and SAS's industry-specific solutions for telcom companies and retail banking. He was founder and chairman of Intrinsic, a campaign management vendor acquired by SAS in March 2001.

\begin{abstract}
The development of technology to support marketing since 1993 has predominantly focused on analytics, campaign management and reporting (collectively marketing automation). Since 2001 there has been the release of a number of technologies aimed at supporting marketing workflow. These solutions, classified by Gartner as marketing resource management (MRM) are starting to address the management of the complex marketing processes that exist in today's multichannel, multibrand marketing functions. This paper looks at how marketing processes are getting more complex and how MRM could provide a valuable tool in managing this complexity. It also explores some of the issues affecting delivery and the potential business benefits of MRM.
\end{abstract}

Shaun Doyle Cognitive Box, Sams Barn, The Greenway, Wantage, Oxon, OX12 8RD, UK.

Tel: +44 (0)1235 821353; Fax: +44 (0)1235 861678; e-mail: shaun.doyle@ cognitivebox.com

\section{INTRODUCTION}

In the early 1990s Intrinsic received a request for information from a building society in Birmingham, UK, for workflow technology that could be used to support the processes in marketing. Neither Intrinsic nor any of the other mainstream campaign management vendors had any propositions in this area. Since then marketing workflow has appeared every now and then, mainly when the larger consultancies are involved in marketing transformation projects. It is only since, roughly, 2001 that there has been a focused attempt by vendors to address this area and release commercial solutions. The initial results appear to be quite positive although there is still a long way to go for this type of technology to become mainstream.

The building society tried to deploy a standard enterprise workflow solution. The lack of clearly-defined standard processes in marketing, the complexity of the interactions of the organisation, both internally and externally, and the limited functionality of the selected solution led, however, to a failed project. 
Things have moved on since the early 1990s. Understanding of the importance of process in marketing has significantly improved and a whole class of new technologies has started to be released. Some of these represent extensions to existing marketing automation solutions (eg Unica Corp) while others have evolved from the agency sector as stand-alone solutions (eg Smartpath). It is clear that the technology has come of age because Gartner has even introduced a magic quadrant and associated acronym - marketing resource management (MRM). ${ }^{1}$

The rest of this paper looks at these new technologies, the issues associated with deployment and the potential benefits. This is likely to be the last bastion for the deployment of technology in marketing.

\section{WHAT IS MARKETING RESOURCE MANAGEMENT?}

Marketing resource management (MRM) is most commonly defined as a set of processes and capabilities that aim to enhance an enterprise's ability to orchestrate and optimise the use of internal and external marketing resources. MRM involves the definition and adoption of processes and software applications to transform and enable an enterprise's ability to plan, budget, execute and measure the impact of enterprise-wide marketing efforts. $^{2}$

\section{WHAT IS DRIVING THE EVOLUTION OF MRM?}

The primary driver for the evolution of MRM solutions is the increasing complexity of managing marketing in a large enterprise.

The following factors have combined to create a step change in the complexity of marketing in today's business environment.

\section{Improved targeting}

The application of statistical techniques to targeting outbound communication activities has led to a drop in the average volume of communications per campaign. In many cases the resulting saving has been re-invested in running more campaigns. The result is that the overall volume of campaigns is increasing. In the author's experience of implementing marketing automation solutions a three to fivefold increase in campaign volumes is typical.

\section{Adoption of event-based marketing}

There has been a wider adoption of event-based campaigns that are triggered by changes in customer behaviour. These event campaigns are characterised by frequently run campaigns which have varying volumes. The ultimate impact on marketing is an increase in the number of campaigns. Where event-based marketing activities have been implemented the increase is more pronounced than above, a five to eightfold increase is common in the first year.

\section{Availability of more communication channels}

The availability of more communication channels and their integration in multichannel campaigns has increased the complexity of the campaign planning, prioritisation and execution. This is often in addition to the increase in volume associated with the previous items.

\section{Move to real-time communications}

In the past, database fresh cycles meant that there was more time for planning. 
The move to real-time marketing with databases that are refreshed in real or near real-time means that the planning cycle has been reduced.

\section{Increased legislation}

There has been a big increase in the legislation controlling what can be included in a communication. This has meant that the compliance process has become more complex and now has to be factored into the campaign planning process. More people now have to be part of the sign-off process. This can be an administrative nightmare, especially if combined with increased campaign velocity.

\section{Increased industry consolidation}

Increased industry consolidation has led to the development of enterprise marketing functions that have to support multiple brands and/or business units. This increases the complexity of the marketing process.

\section{Lack of process support in marketing automation solutions}

The wider use of marketing automation technology has help to automate many activities - particularly support for the campaign management, analytical and reporting activities — but there has been limited support for other processes such as:

- project management

- supplier management

— product management

- competitive analysis

- planning.

The introduction of these technologies has tended to be a catalyst for process review and enhancement. There has not, however, really been any appropriate technology support for the wider process issues or a commitment by the business to address the wider process issues in marketing.

\section{Continuous business pressure to increase productivity}

In addition to increased complexity there is always a business pressure to improve the productivity of the marketing team.

\section{HOW MRM ADDRESSES THESE ISSUES}

The core technologies that underpin MRM are workflow. In simple terms these technologies allow:

- processes to be decomposed into a series of tasks

- the tasks to be linked together in a sequence

- the tasks to be linked to an individual or role.

Once created, these process maps allow the technology to prompt a user with a list of tasks to be completed. As the user completes a task the system records the status. The user is then prompted with the next task. The underlying data that are created as part of each task are then used to drive management reporting. In addition these technologies allow both internal and external users to share objects, eg documents. (Note: In reality the technologies are more complex than described here but the basic principles apply.)

\section{WHAT ARE THE POTENTIAL BUSINESS BENEFITS OF MRM?}

The following are some of the potential benefits of MRM. 


\section{Standardised processes in marketing}

The introduction of MRM forces

organisations to standardise marketing processes. This ensures a consistent approach to each process supported. (Note: It must be recognised that it may not be appropriate to implement MRM for all marketing processes.)

\section{Definition and sharing of best practices}

The review process during the development stage allows an organisation to review critically current processes and to determine best practice. These can then be encapsulated in the delivery and applied across the business.

Once deployed the MRM solution provides valuable metrics that can be used to refine existing processes and develop new processes.

\section{Monitoring of processes}

One of the key benefits of the latest MRM technologies is that they produce a wide range of metrics that allow management to monitor the execution of one or more processes. These metrics can ensure effective management of the business.

\section{Reduction of errors and rework}

One of the consequences of MRM is that the number of errors made and the amount of rework can be reduced. This is primarily the result of the system supporting what would normally be a manual process.

\section{WHO IS TYPICALLY AFFECTED?}

This really depends on how extensively the MRM technologies are deployed but typically the functions that would be impacted are listed below.
Within the marketing function:

- product management

- marketing communications

- competitive intelligence

— database marketing

- marketing analysis

— marketing executive.

Within the wider organisation:

- legal (compliance)

- finance (budget)

- channel management (eg call centre management)

- sales management

- IT.

Externally to the organisation:

— advertising agencies

- external telemarketing agencies

— print houses

— list brokers

— data management suppliers.

While MRM embraces a variety of different aspects of marketing, its greatest effects are felt by the core group of marketing staff that is focused on daily execution: production and fulfilment workers, compliance managers and suppliers. Using MRM, they can get a personalised view of their daily tasks and deliverables, the status of document review and approval and can manage resource and schedule changes. MRM typically addresses all of the tasks involved in day-to-day marketing operations, unifying them and embedding efficiencies.

\section{WHAT PROCESSES ARE TYPICALLY SUPPORTED?}

The following processes are typically supported by MRM: 
- marketing plan management

- campaign plan management

- campaign management

- product development management

- competition monitoring

- brand development management

— marketing performance monitoring.

\section{WHAT EVIDENCE IS THERE THAT MRM WORKS?}

It is fair to say that MRM is in the early adopter stage, with few companies having fully implemented solutions and run them for long periods of time.

When Gartner surveyed companies with MRM implementations, 100 per cent reported improved efficiencies and 93 per cent improved effectiveness the highest level of improvement ever reported for a new software category. ${ }^{3}$

Specifically, better use of marketing assets resulted in: $f^{2 \mathrm{~m}}$ savings in annual agency fees for one insurance company; an auto parts manufacturer reduced its packaging design cycle from three to four weeks to one to three days; and a pharmaceutical company decreased the time required for marketing campaign creative development approvals from 14 to two weeks. ${ }^{4}$

\section{WHICH SECTORS HAVE BEEN EARLY ADOPTERS OF MRM?}

According to industry analysts, ${ }^{5}$ the key driver for MRM is the increasing complexity of marketing. The need cuts across all industries and affects those organisations that have experienced consolidation, brand proliferation and heavy regulation. The following sectors have been the early adopters:

- automotive

- consumer packaged goods

- pharmaceuticals

- financial services
- retail

— high technology companies.

\section{WHAT ARE THE LIKELY DEPLOYMENT ISSUES?}

The following are some of the key issues that will need to be addressed by those looking at deploying MRM technologies.

\section{Lack of documentation of current processes}

Many organisations do not have well-documented processes in marketing. This will be a hurdle for rapid deployment and will have to be addressed as part of the project. The author suggests that organisations use an external resource that is experienced in this area.

\section{Complexity of marketing processes}

The number and complexity of the processes in marketing means that tackling all processes from the first day will be fraught with danger.

Organisations are advised to focus on a few key processes then expand into other areas and look for processes that provide quick win financial benefits.

\section{Impact on organisation and suppliers}

Implementing MRM will have an impact on a wide audience both internal and external to the organisation. All parties should be fully involved and committed to the project. Taking an evolutionary approach rather than a big bang approach it will take time to get the delivery process smooth, but this is the recommended route.

\section{Lack of product stability}

There are a number of MRM vendors in the marketplace and there will be a 
number of other new entrants over the next year or so. There have been a number of problems with product stability and this is likely to continue as new players rush products to market. It is important to make sure that due diligence is rigorous, particularly with new players.

\section{Vendor viability}

Vendor viability will be an issue while the market is immature. As with product stability, due diligence should be exhaustive.

\section{WHAT TO LOOK FOR IN MRM TECHNOLOGIES}

The following are some of the key things to look for in selecting a MRM technology partner:

- ability to configure the product

- absence or limited use of customer specific code

- proven scalability

- modular design and architecture

- simple deployment capability.

\section{SUPPLIERS OF MRM TECHNOLOGY}

The following are examples of MRM technology vendors:

- Aprimo

- Smartpath

- Unica

- Elateral

- Veridiem.
As highlighted earlier in the paper, due diligence is always required when selecting any vendor.

\section{CONCLUSION}

The increasing complexity of marketing in a multichannel, real-time environment and the business pressure to increase the productivity of marketing teams means that it is essential that the support in marketing for business processes be improved. MRM technologies appear to address some of the key issues. The author expects that this last bastion for technology support in marketing, ie process support, will be addressed over the next few years. In selecting a possible vendor for MRM look for financial viability, product stability and functionality.

MRM will be most appropriate for large organisations with high volumes of campaigns ( $>100 /$ year), but as this technology becomes a commodity it will become a standard part of the technology framework that supports a typical marketing function.

\section{References}

1 Marcus, C. (2003) 'Marketing resource management - Magic quadrant', VP Research, Gartner, www.gartner.com, February (M-193829).

2 Marjot, B. (2003) 'Marketing resource management', The Delivery Partnership, May, www.thedeliverypartnership.com.

3 Marcus (2003) op. cit.

4 www.smartpath.com case studies, 2003.

5 Marcus (2003) op. cit. 